\title{
Théologiques
}

\section{Présentation du volume}

\section{Alain Gignac}

Volume 21, numéro 1, 2013

URI : https://id.erudit.org/iderudit/1025465ar

DOI : https://doi.org/10.7202/1025465ar

Aller au sommaire du numéro

Éditeur(s)

Faculté de théologie et de sciences des religions, Université de Montréal

ISSN

1188-7109 (imprimé)

1492-1413 (numérique)

Découvrir la revue

Citer ce document

Gignac, A. (2013). Présentation du volume. Théologiques, 21(1), 5-6. https://doi.org/10.7202/1025465ar

Ce document est protégé par la loi sur le droit d'auteur. L'utilisation des services d'Érudit (y compris la reproduction) est assujettie à sa politique d'utilisation que vous pouvez consulter en ligne.

https://apropos.erudit.org/fr/usagers/politique-dutilisation/
Cet article est diffusé et préservé par Érudit.

Érudit est un consortium interuniversitaire sans but lucratif composé de l’Université de Montréal, l'Université Laval et l'Université du Québec à Montréal. Il a pour mission la promotion et la valorisation de la recherche. https://www.erudit.org/fr/ 


\section{Présentation du volume}

À l'origine de ce numéro thématique de Théologiques, il y a un souhait consensuel des membres de l'Association catholique des études bibliques au Canada (ACÉBAC) : tenir son $69^{\mathrm{e}}$ congrès annuel sur le thème "Bible et archéologie» (5-7 juin 2012, Pierrefonds, région de Montréal) ${ }^{1}$. L'ACÉBAC réunit ainsi chaque année les chercheurs universitaires francophones du Canada qui œuvrent dans le domaine biblique, leurs étudiants ainsi que des intervenants en pastorale ayant une formation biblique. De tradition catholique, l'Association est maintenant résolument œcuménique - et avant tout scientifique, faisant place à la discussion et à une diversité d'approches, tant aux plans méthodologique qu'herméneutique, au carrefour de l'histoire, de la littérature et de la théologie.

Sensibilisés de longue date à l'importance de l'archéologie pour l'interprétation des textes bibliques, les membres de l'ACÉBAC n'en étaient pas moins conscients qu'ils avaient besoin d'une mise à jour dans ce domaine, tant le cloisonnement disciplinaire est encore - hélas! - effectif, et tant les choses bougent rapidement. Or, la préparation du congrès et son déroulement ont révélé deux choses: 1) la richesse et la complexité du thème choisi; 2) la rareté de l'expertise en milieu exégétique francophone. Je fonde entre autres ce diagnostic sur un symptôme: il est apparu rapidement, lorsqu'il nous a fallu concrétiser le souhait de l'assemblée générale dans un programme concret, que les seules ressources des membres de notre association seraient insuffisantes. Peu ont eu l'occasion de faire un stage sur le terrain au cours de leur formation; aucun n'a une pratique archéologique conséquente; quelques-uns seulement investissent temps et énergie à se documenter dans le domaine. Ainsi, outre trois collègues de l'ACÉBAC férus d'archéologie: Robert David, Jean-Paul Michaud, Pierluigi Piovanelli, nous avons fait appel lors du congrès à des experts extérieurs: Daniel Gerber, exégète français ${ }^{2}$; Thierry Petit, archéologue québécois; Hedwige Rouillard-Bonraisin, historienne française. Finalement, au moment de publier les interventions du congrès, nous avons

1. On peut consulter les programmes des différents congrès de l'ACÉBAC sur le site web de l'association: <http://www.interbible.org/acebac/index2.htm>.

2. Soulignons que la participation du professeur Gerber s'inscrit dans la cadre d'une collaboration avec le vis-à-vis francophone européen de l'ACÉBAC: l'Association catholique française pour l'étude de la Bible (ACFEB). 
pensé élargir l'éventail par un appel de contributions - ce qui explique le délai de publication. Au final, cinq articles du présent dossier ont pour origine une communication donnée au congrès de l'ACÉBAC, cinq ont été rédigés subséquemment. Ce numéro, officiellement daté de 2013, paraît donc au premier semestre 2014.

Une fois n'est pas coutume: vu l'ampleur du numéro, aucun article hors-thème n'est publié.

Alain Gignac,

Président de l'ACÉBAC et directeur du numéro 